\title{
The influence of different agitation techniques on the adsorption kinetics of 4-chlorophenol on granular activated carbon
}

\author{
Krzysztof Kuśmierek ${ }^{1}$ - Andrzej Świątkowski ${ }^{1}$
}

Received: 30 March 2015/ Accepted: 21 May 2015/Published online: 3 June 2015

(C) The Author(s) 2015. This article is published with open access at Springerlink.com

\begin{abstract}
The influence of different agitation techniques on the adsorption of organic compounds, represented by 4-chlorophenol, onto granular activated carbon was investigated. The effect of the flask type and the type of agitator, including a laboratory shaker, mechanical agitator, magnetic stirrer as well as mixing with gas bubbles, was studied. The results of adsorption kinetics demonstrate that the adsorption process of 4-chlorophenol on the activated carbon follows a pseudo-second order kinetic model closely. The adsorption equilibrium was reached faster in the Erlenmeyer flask than in the round-bottomed flask. At the same agitation speed (200 rpm), the better adsorption rate and adsorption efficiency were observed using the mechanical and magnetic stirrers than the laboratory shaker. At the gas flow rate of $1.5 \mathrm{dm}^{3} \mathrm{~min}^{-1}$, the mixing with the air or nitrogen bubbles was comparable with the agitation when using mechanical and magnetic stirrers at $200 \mathrm{rpm}$. The effect of the agitation speed on the adsorption of the 4-chlorophenol by the activated carbon was also tested. The kinetic experiments were carried out at 100, 200, 300 and $500 \mathrm{rpm}$ and it was found that the adsorption rate increases with the increase in the agitation speed. As the stirring rate increased from 100 to $500 \mathrm{rpm}$, the adsorption rate constants increased from 0.577 to $1.264 \mathrm{~g} \mathrm{mmol}^{-1} \mathrm{~h}^{-1}$ (mechanical agitator) and from 0.560 to $1.231 \mathrm{~g} \mathrm{mmol}^{-1} \mathrm{~h}^{-1}$ (magnetic stirrer), respectively. The experimental results demonstrate that the agitation affects the adsorption kinetics significantly as well as the adsorption equilibrium of the organic compounds on the activated carbon, and should be taken into account in such studies.
\end{abstract}

Keywords 4-Chlorophenol - Activated carbon - Adsorption kinetics · Agitation

Krzysztof Kuśmierek

krzysztof.kusmierek@wat.edu.pl

1 Institute of Chemistry, Military University of Technology, 00-908 Warsaw, Poland 


\section{Introduction}

The adsorption process by solid adsorbents is one of the most efficient methods for the removal of organic contaminants from water [1-3]. Adsorption is attractive for its relative flexibility and simplicity of design, low cost, ease of operation and regeneration as well as the no or low generation of toxic substances. Activated carbons are now the most commonly used adsorbents of proven adsorption efficiency for organic pollutants due to their high surface area, pore volume, and pore size distribution [4]. The effectiveness of the adsorption of organic compounds on the activated carbons depends on their pore texture and surface chemistry, the physicochemical properties of the adsorbate (molecular mass, solubility, polarity, type of functional groups), the solution chemistry (ionic strength, $\mathrm{pH}$ ) and the temperature [4]. The impact of most of these factors on the kinetics and adsorption equilibrium of different organic pollutants is well known and well documented but some still require examination.

The adsorption experiments are usually carried out in Erlenmeyer flasks containing a fixed volume of the adsorbate solutions (with different initial concentrations) and a known mass of the adsorbent. The thus prepared samples are then shaken until equilibrium is reached. The authors, however, rarely provide the conditions under which the samples are mixed. The effect of the agitation on the adsorption is usually ignored. Only a few authors studied the effect of the agitation speed on the adsorption [5-11]. However, to our knowledge, the effect of the different mixing techniques on the adsorption has not so far been studied.

The purpose of this study is to compare the different agitation techniques and their impact on the adsorption kinetics and adsorption capacity of an organic pollutant on activated carbon. The samples were mixed by the gas bubbles, using a laboratory shaker, a mechanical (paddle) agitator as well as a magnetic stirrer. The effect of the agitation speed was also examined. We chose 4-chlorophenol (4-CP) as the target contaminant because it is poisonous to aquatic life, plants and humans at low level [12] and is commonly found in drinking water [13]. In addition, the adsorption of 4-chlorophenol on activated carbon is well described [7, 14-23]. 4-Chlorophenol was adsorbed onto various modified and unmodified activated carbons; the effect of other factors affecting the adsorption of the 4-CP on activated carbon including the ionic strength [24] and $\mathrm{pH}$ [25] has also been described.

\section{Experimental}

\section{Reagents and apparatus}

The 4-chlorophenol (4-CP), CAS No. 106-48-9, was purchased from Sigma (St Louis, USA). The acetic acid (CAS No. 64-19-7), hydrochloric acid (CAS No. 7647-01-0), hydrofluoric acid (CAS No. 7664-39-3) and HPLC-grade acetonitrile (CAS No. 75-05-8) were from Avantor Performance Materials (Gliwice, Poland). 
As the adsorbent the granular activated carbon, Organosorb-10 (Roeselare, Belgium) was chosen. Prior to use, the activated carbon was pretreated by ash removal with the use of $\mathrm{HCl}$ and $\mathrm{HF}$ concentrated acids and rinsed several times with deionized water. Details are described by Korver [26]. The adsorbent was then dried in an oven at $130{ }^{\circ} \mathrm{C}$ to a constant weight and kept in a desiccator for further study.

The Brunauer-Emmett-Teller surface area $\left(S_{\mathrm{BET}}\right)$ of the activated carbon was obtained on the basis determined by the nitrogen low-temperature adsorptiondesorption isotherm (ASAP 2020, Micromeritics, Norcross, USA).

In the adsorption studies, samples were mixed by the air (AG204 aquarium pump, PRO-TECH, Wschowa, Poland) and the nitrogen bubbles (gas cylinder, 99.9\%, Multax, Warsaw, Poland) as well as by a laboratory shaker (WL-972, JWE Electronic, Warsaw, Poland), a mechanical agitator (Heidolph RZR 2020, Schwabach, Germany) and a magnetic stirrer (RCT Standard, IKA-POL, Warsaw, Poland).

\section{Adsorption experiments}

The adsorption experiments were carried out in Erlenmeyer flasks (or in the roundbottomed flasks) containing $0.05 \mathrm{~L}$ of the $4-\mathrm{CP}$ solution and $0.025 \mathrm{~g}$ of the activated carbon. The kinetic studies were conducted for an initial 4-CP concentration of $1.0 \mathrm{mmol} \mathrm{L}{ }^{-1}$ at $25^{\circ} \mathrm{C}$. Aqueous samples were taken at different intervals of time and the concentration of 4-CP was measured chromatographically.

\section{Analytical method}

The concentration of 4-CP was measured by high-performance liquid chromatography with UV detection (Shimadzu LC-20, Kyoto, Japan). The chromatographic analysis was carried out using a Phenomenex Luna C18, $2.0 \times 150 \mathrm{~mm}, 3 \mu \mathrm{m}$ column (Torrance, CA, USA). The chromatographic conditions were as follows: mobile phase-acetonitrile/water adjusted to $\mathrm{pH} 3.0$ with acetic acid (50/50, v/v);

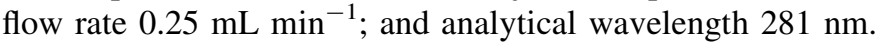

\section{Calculations}

The amount of 4-CP adsorbed onto the activated carbon at time $t, q_{\mathrm{t}}\left(\mathrm{mmol} \mathrm{g}^{-1}\right)$, was calculated by the following equation:

$$
\mathrm{q}_{\mathrm{t}}=\mathrm{V} \frac{\mathrm{C}_{0}-\mathrm{C}_{\mathrm{t}}}{\mathrm{m}}
$$

Here $C_{0}$ and $C_{\mathrm{t}}$ are the initial concentration and the concentration at the time $\mathrm{t}$ $\left(\mathrm{mmol} \mathrm{L} \mathrm{L}^{-1}\right), V$ is the volume of the solution (L) and $m$ is the mass of the adsorbent (g).

The adsorption of the 4-CP at equilibrium, $q_{\mathrm{e}}\left(\mathrm{mmol} \mathrm{g}^{-1}\right)$, was calculated by the following equation: 


$$
\mathrm{q}_{\mathrm{e}}=\mathrm{V} \frac{\mathrm{C}_{0}-\mathrm{C}_{\mathrm{e}}}{\mathrm{m}}
$$

Here $C_{\mathrm{e}}$ is the equilibrium concentration of the 4-CP $\left(\mathrm{mmol} \mathrm{L}^{-1}\right)$ in the solution. For the description of the experimental data, the equations of the pseudo-first and pseudo-second order were considered. The pseudo-first order kinetic model is expressed as [27]:

$$
\log \left(\mathrm{q}_{\mathrm{e}}-\mathrm{q}_{\mathrm{t}}\right)=\log \mathrm{q}_{\mathrm{e}}-\frac{\mathrm{k}_{1}}{2.303} \mathrm{t}
$$

Here $k_{1}$ is the pseudo-first order rate constant of adsorption $\left(\mathrm{h}^{-1}\right)$. The values of $k_{1}$ were calculated from the plots of $\log \left(q_{\mathrm{e}}-q_{\mathrm{t}}\right)$ versus $t$.

The pseudo-second order equation has the form [28]:

$$
\frac{\mathrm{t}}{\mathrm{q}_{\mathrm{t}}}=\frac{1}{\mathrm{k}_{2} \mathrm{q}_{\mathrm{e}}^{2}}+\frac{1}{\mathrm{q}_{\mathrm{e}}} \mathrm{t}
$$

Here $k_{2}$ is the pseudo-second order rate constant $\left(\mathrm{g} \mathrm{mmol}^{-1} \mathrm{~h}^{-1}\right)$. The values of $k_{2}$ were calculated from the plots of $t / q_{\mathrm{t}}$ versus $t$.

All the experiments were carried out in triplicate under identical conditions and the average values were used for further calculations. The mean and standard deviation of the three replicates were reported and the data obtained were analyzed using t-test and/or ANOVA with a Tukey test. The differences between any pair of treatment means were tested using the least significant difference test with the significance level at 0.05 .

\section{Results and discussion}

\section{Adsorbent properties}

The nitrogen adsorption/desorption isotherm for the deashed Organosorb-10 activated carbon was determined from the $\mathrm{N}_{2}$ adsorption isotherm measured at

Fig. 1 Nitrogen adsorptiondesorption isotherm on Organosorb-10 activated carbon at $77.4 \mathrm{~K}$

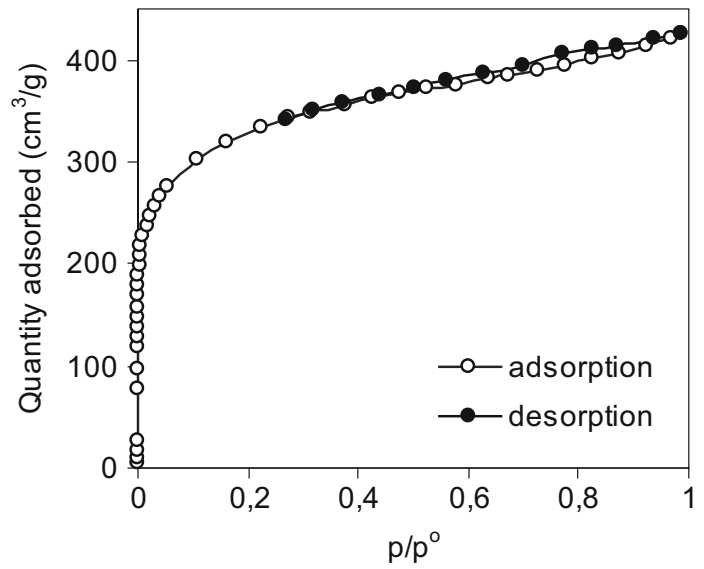


$77 \mathrm{~K}$ and the results are presented in Fig. 1. The specific surface area was calculated from the BET-equation and was found to be $1138 \mathrm{~m}^{2} \mathrm{~g}^{-1}$. The total pore volume $V_{\mathrm{t}}$ was $0.551 \mathrm{~cm}^{3} \mathrm{~g}^{-1}$ while the micropore volume $V_{\mathrm{mi}}$ and mesopore volume $V_{\mathrm{me}}$ were 0.358 and $0.191 \mathrm{~cm}^{3} \mathrm{~g}^{-1}$, respectively.

\section{Adsorption studies}

\section{Erlenmeyer flask versus round-bottomed flask}

In the first step, the effect of the flask type (flask shape) on the adsorption kinetics of 4-CP on activated carbon was examined. The adsorption experiments were performed simultaneously in an Erlenmeyer flask as well as in a round-bottomed flask each one containing $0.05 \mathrm{~L}$ of the 4-CP solution and $0.025 \mathrm{~g}$ of the activated carbon. The solutions were then agitated on a laboratory shaker at $200 \mathrm{rpm}$ at $25{ }^{\circ} \mathrm{C}$. The adsorption kinetic curves of the 4-chlorophenol, the plot of $q_{\mathrm{t}}=\mathrm{f}(t)$, are shown in Fig. 2. In both cases, the adsorption equilibria were achieved after about $4 \mathrm{~h}$. The kinetic data were fitted into the pseudo-first order and pseudo-second order models. The correlation coefficients for the pseudo-first order kinetic model are relatively low ( 0.934 for the Erlenmeyer flask and 0.981 for the round-bottomed flask), whereas the $R^{2}$ values for the pseudo-second order kinetic model are higher than 0.99. This indicates that the adsorption process of the 4-CP onto the activated carbon fits the second order kinetic model. Similar results were obtained by other authors [7, 18, 20-22, 25]. All the results obtained from the pseudo-first order kinetic model were weaker in each case, and therefore they were not taken into account and are not shown. For the comparison and interpretation of the results only the pseudo-second order rate constants were used. The $k_{2}$ obtained for the 4-CP adsorption in the Erlenmeyer flask was significantly higher $(p<0.05)$ than that obtained in the round-bottomed flask $(0.597 \pm 0.013$ versus $0.442 \pm 0.017 \mathrm{~g} \mathrm{~m}$ $\mathrm{mol}^{-1} \mathrm{~h}^{-1}$, respectively). This indicates that the flask type affects the adsorption kinetics. The adsorption equilibrium was reached faster in the Erlenmeyer flask than

Fig. 2 The effect of flask type on the adsorption kinetics of 4-CP on granular activated carbon at $25{ }^{\circ} \mathrm{C}$. Experimental conditions: initial concentration of 4-CP $1.0 \mathrm{mmol} \mathrm{L}^{-1}$, mass of the adsorbent $0.025 \mathrm{~g}$, solution volume $0.05 \mathrm{~L}$, laboratory shaker, agitation speed $200 \mathrm{rpm}$

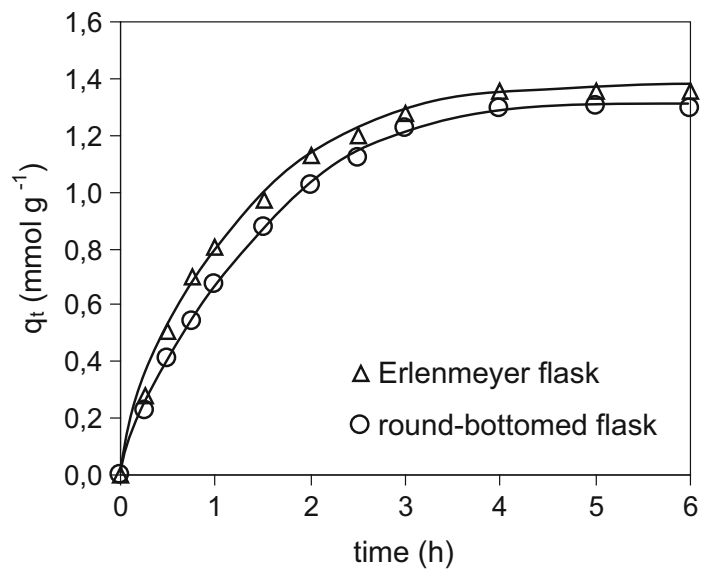


in the round-bottomed flask. It is probably due to the fact that in the Erlenmeyer flask the adsorbent is free to move around the bottom of the glass, whereas in the round-bottomed flask grains of the activated carbon are concentrated in one place (at the lowest point of the flask) which reduces their availability to the adsorbate molecules.

\section{Effect of mixing techniques}

In order to study the effect of the mixing techniques on the adsorption of 4-CP, the Erlenmeyer flasks containing the adsorbents and adsorbate solutions were agitated at $200 \mathrm{rpm}$ using the laboratory shaker, the mechanical agitator and the magnetic stirrer. The results are presented in Fig. 3. The pseudo-second order rate constants were $0.597 \pm 0.013,0.701 \pm 0.005$ and $0.691 \pm 0.015 \mathrm{~g} \mathrm{mmol}^{-1} \mathrm{~h}^{-1}$ for the laboratory shaker, the mechanical agitator and the magnetic stirrer, respectively. The difference in the adsorption rate between the mechanical agitator and the magnetic stirrer is not statistically significant $(p=0.34)$. In both these cases, the adsorption occurred faster than using the laboratory shaker. The differences between the laboratory shaker and the mechanical agitator as well as between the laboratory shaker and the magnetic stirrer were statistically significant (ANOVA-Tukey test). The same correlation was observed in the adsorption capacities $\left(q_{\mathrm{e}}\right)$, which were as follows: 1.359 (laboratory shaker), 1.442 (mechanical agitator) and 1.430 (magnetic stirrer) $\mathrm{mmol} \mathrm{g}^{-1}$. All these results indicate that the mixing technique plays an important role in both the kinetics and adsorption equilibrium. Better results were observed using the mechanical and magnetic stirrers than the laboratory shaker. The increase in the adsorption rate and adsorption capacity in the case of the magnetic and mechanical stirrers was a result of the physical contact between the stir bar or stirrer paddles with the activated carbon. As a result, the adsorbent material gets reduced in size and the adsorption sites are more easily accessible to the adsorbate molecules. An increase in both the adsorption kinetics and the adsorption capacity

Fig. 3 Comparison of different mixing techniques on the adsorption kinetics of 4-CP on granular activated carbon at 200 rpm. Experimental conditions: initial concentration of 4-CP $1.0 \mathrm{mmol} \mathrm{L}^{-1}$, mass of the adsorbent $0.025 \mathrm{~g}$, solution volume $0.05 \mathrm{~L}$, temperature $25^{\circ} \mathrm{C}$

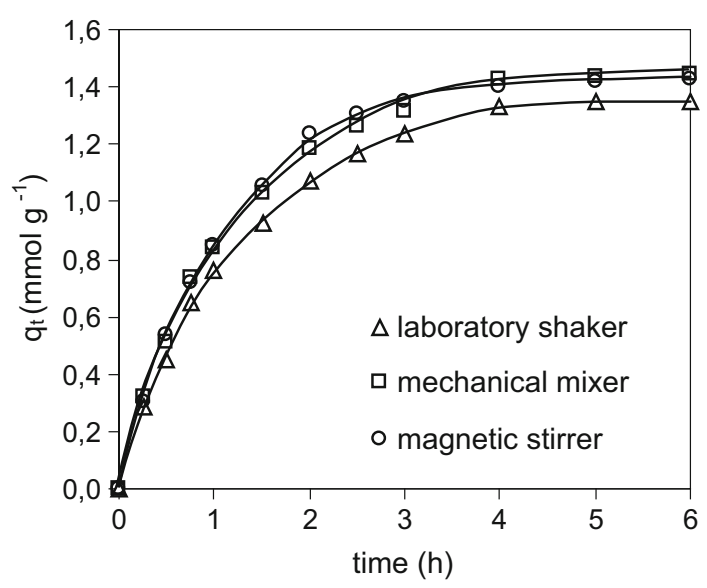


of 4-CP with a decrease in the particle size of the activated carbon was reported by Koumanova et al. [7, 15].

\section{Effect of agitation speed}

The influence of the agitation speed on the adsorption of 4-chlorophenol from the aqueous solution was also studied. The adsorbent dose, initial 4-CP concentration and temperature were kept constant. The study was conducted varying the speed from 100 to $500 \mathrm{rpm}$ using a mechanical agitator and magnetic stirrer. The effect of the agitation rate on the adsorption of 4-CP is shown in Fig. 4 and Table 1.

As can be seen, the adsorption rate was highly influenced by the agitation ratethe adsorption rate increases significantly with the agitation speed. As the stirring rate increased from 100 to $500 \mathrm{rpm}$ the $k_{2}$ value increased from 0.577 to $1.264 \mathrm{~g} \mathrm{mmol}^{-1} \mathrm{~h}^{-1}$ (mechanical agitator) and from 0.560 to $1.231 \mathrm{~g} \mathrm{mmol}^{-1} \mathrm{~h}^{-1}$ (magnetic stirrer), respectively. At the same agitation speed, the differences between the mechanical agitator and magnetic stirrer were not statistically significant $(p>0.05)$. With the increasing of the agitation speed, the rate of diffusion of the 4-CP molecules from the bulk liquid to the liquid boundary layer surrounding the activated carbon particle become higher because of an enhancement of the turbulence and a decrease of the thickness of the liquid boundary layer. This effect may be additionally enhanced by the greater fragmentation of the adsorbent particles which accompanies the increased agitation speed. In these studies, the particle size of the adsorbent before and after the experiment was not measured, but the effect of the particle size of the activated carbon on the adsorption kinetics of 4-CP is well documented [7, 15]. The increase of the adsorption rate with the agitation speed was also described for the adsorption of the basic dye on the activated clay [6] as well as the acetic acid [5], imidacloprid [9] and 4-chlorophenol $[7,15]$ on the activated carbon.
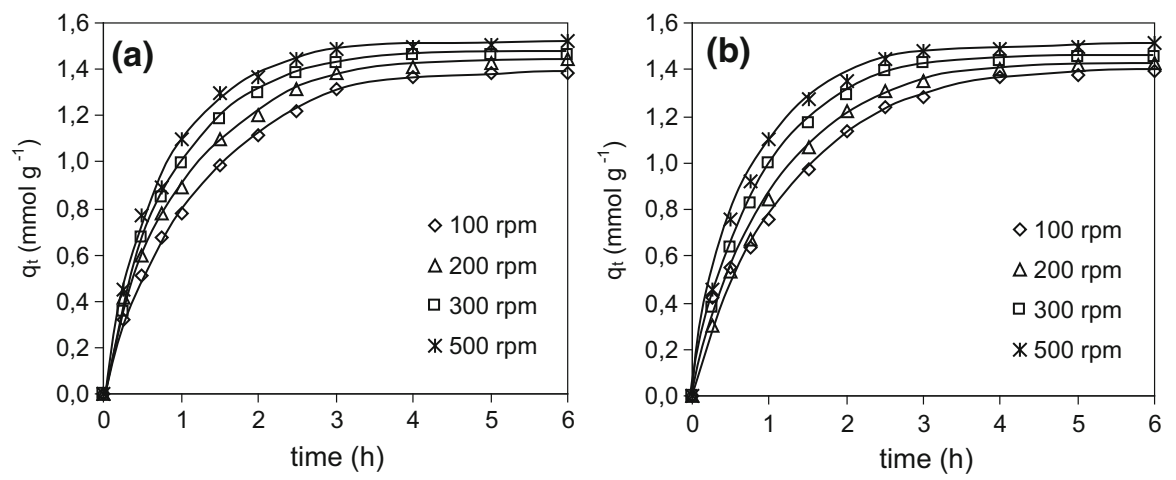

Fig. 4 The effect of agitation speed on the adsorption kinetics of 4-CP on granular activated carbona mechanical agitator, b magnetic stirrer. Experimental conditions: initial concentration of 4-CP $1.0 \mathrm{mmol} \mathrm{L}^{-1}$, mass of the adsorbent $0.025 \mathrm{~g}$, solution volume $0.05 \mathrm{~L}$, temperature $25^{\circ} \mathrm{C}$ 
Table 1 The influence of agitation speed on adsorption kinetics and adsorption equilibrium of 4-CP on granular activated carbon

\begin{tabular}{llllll}
\hline $\begin{array}{l}\text { Agitation } \\
\text { speed }(\mathrm{rpm})\end{array}$ & \multicolumn{2}{l}{ Mechanical agitator } & & \multicolumn{2}{l}{ Magnetic stirrer } \\
\cline { 2 - 3 } \cline { 5 - 6 } & $\begin{array}{l}k_{2} \pm \mathrm{SD} \\
\left(\mathrm{g} \mathrm{mmol}^{-1} \mathrm{~h}^{-1}\right)\end{array}$ & $\begin{array}{l}q_{\mathrm{e}} \pm \mathrm{SD} \\
\left(\mathrm{mmol} \mathrm{g}^{-1}\right)\end{array}$ & & $\begin{array}{l}k_{2} \pm \mathrm{SD} \\
\left(\mathrm{g} \mathrm{mmol}^{-1} \mathrm{~h}^{-1}\right)\end{array}$ & $\begin{array}{l}q_{\mathrm{e}} \pm \mathrm{SD} \\
\left(\mathrm{mmol} \mathrm{g}^{-1}\right)\end{array}$ \\
\hline 100 & $0.577 \pm 0.007$ & $1.385 \pm 0.050$ & & $0.560 \pm 0.022$ & $1.391 \pm 0.066$ \\
200 & $0.701 \pm 0.005$ & $1.442 \pm 0.034$ & & $0.691 \pm 0.015$ & $1.430 \pm 0.053$ \\
300 & $0.850 \pm 0.033$ & $1.464 \pm 0.052$ & & $0.815 \pm 0.025$ & $1.453 \pm 0.055$ \\
500 & $1.264 \pm 0.097$ & $1.520 \pm 0.051$ & & $1.231 \pm 0.073$ & $1.510 \pm 0.051$ \\
\hline
\end{tabular}

The data presented in Table 1 also show that the agitation rate affects not only the adsorption kinetics but also the removal efficiency of 4-CP from the water. The adsorption capacity increased from 1.385 to $1.520 \mathrm{mmol} \mathrm{g}^{-1}$ (mechanical agitator) and from 1.391 to $1.510 \mathrm{mmol} \mathrm{g}^{-1}$ (magnetic stirrer) with an increasing agitation speed from 100 to $500 \mathrm{rpm}$. A similar correlation was observed by Koumanova et al. [7] who observed an increase in the adsorption capacity of 4-CP from 20.06 to $23.04 \mathrm{mg} \mathrm{g}^{-1}$ with an increasing agitation rate from 300 to $600 \mathrm{rpm}$. However, some authors have reported that the adsorption increases with increasing agitation speeds only up to a certain limit, beyond which there is no significant increase in the adsorption capacity $[5,6,11]$. In some cases, a decrease in the adsorption capacity at a higher agitation rate was observed [8,10]. As suggested by the authors [8], this is due to the fact that at a very high agitation speed, the kinetic energy of both the adsorbate molecules and the adsorbent particles increased enough that they collide with each other hastily resulting in the detachment of the loosely bound adsorbate molecules.

\section{Mixing using gas bubbles}

The effect of mixing the solution by gas bubbles on the adsorption of 4-CP on the activated carbon was investigated. The solutions of 4-CP in two-neck roundbottomed flasks were mixed using air or nitrogen flowing at the same rate of $1.5 \mathrm{dm}^{3} \mathrm{~min}^{-1}$. The initial concentration of the 4-CP was $1 \mathrm{mmol} \mathrm{L}^{-1}$ and the mass of the activated carbon was $0.025 \mathrm{~g}$. As the use of compressed nitrogen from cylinders resulted in a substantial decrease in the temperature of the solution, in order to preserve the same conditions, the experiments were conducted with the use of bath water at $25{ }^{\circ} \mathrm{C}$. For obvious reasons, all the experiments were conducted in open flasks. As the loss of the adsorbate could be due to the evaporation of the 4-CP, the blank tests without the adsorbent addition were tested. The results showed that during the considered period of time $(6 \mathrm{~h})$ the amount of the 4-CP in the solution was constant. The concentration varied $\pm 3 \%$ which was due to measurement error rather than the evaporation of the 4-CP from the solution. It is also important to point out that at higher concentrations, as well as at higher temperatures, the evaporation of the 4-CP can be significant. 
The adsorption kinetic curves of 4-CP are shown in Fig. 5. The adsorption capacities were found to be $1.520 \mathrm{mmol} \mathrm{g}^{-1}$ (air) and $1.545 \mathrm{mmol} \mathrm{g}^{-1}$ (nitrogen). The pseudo-second order kinetic constants were $0.672 \pm 0.005 \mathrm{~g} \mathrm{mmol}^{-1} \mathrm{~h}^{-1}$ during the mixing with air and $0.669 \pm 0.031 \mathrm{~g} \mathrm{mmol}^{-1} \mathrm{~h}^{-1}$ while mixing with nitrogen. At the 0.05 level, the difference of the $k_{2}$ values was not significantly different, and thus at the same flow rate the gas type is not relevant. Comparing these kinetic constants with the results obtained earlier, it can be concluded that the mixing with air/nitrogen bubbles is comparable to mixing using mechanical and magnetic stirrers at $200 \mathrm{rpm}$.

\section{Conclusions}

This paper demonstrates the influence of different agitation techniques on the adsorption of 4-chlorophenol onto granular activated carbon. The effect of the flask type and the type of agitator including a laboratory shaker, mechanical agitator, magnetic stirrer as well as mixing with gas bubbles (air or nitrogen) was investigated.

The kinetic data were fitted to the pseudo-first order and pseudo-second order models, and it was found that the best fitting corresponded to the pseudo-second order kinetic model. The adsorption equilibrium was reached faster in the Erlenmeyer flask than in the round-bottomed flask. At the same agitation speed (200 rpm), a better adsorption rate and adsorption efficiency were observed using the mechanical and magnetic stirrers than the laboratory shaker as a result of the reduction in the particle size of the adsorbent due to its contact with the stirrer paddles or the stir bar. At the same flow rate $\left(1.5 \mathrm{dm}^{3} \mathrm{~min}^{-1}\right)$, the gas type (air or nitrogen) is not relevant. The mixing with gas bubbles was comparable to the agitation using the mechanical and magnetic stirrers at $200 \mathrm{rpm}$. The effect of the agitation speed on the adsorption of 4-chlorophenol on the activated carbon was also tested. The kinetic experiments were carried out at 100, 200, 300 and $500 \mathrm{rpm}$ and it was found that the adsorption rate increases with an increase in the agitation speed.

Fig. 5 The effect of solution mixing by air or nitrogen bubbles on the adsorption of 4-CP on granular activated carbon. Experimental conditions: initial concentration of 4-CP $1.0 \mathrm{mmol} \mathrm{L}^{-1}$, mass of the adsorbent $0.025 \mathrm{~g}$, solution volume $0.05 \mathrm{~L}$, temperature $25^{\circ} \mathrm{C}$, gas flow rate $1.5 \mathrm{dm}^{3} \min ^{-1}$

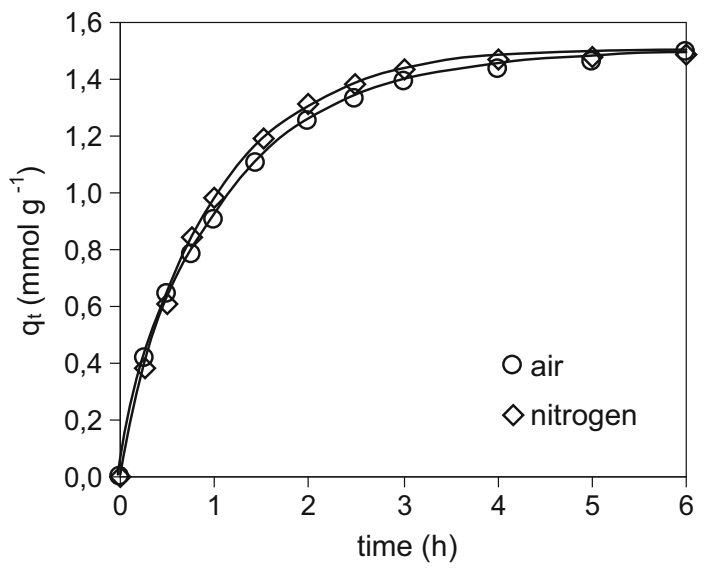


The lowest values of $k_{2}\left(0.442 \mathrm{~g} \mathrm{mmol}^{-1} \mathrm{~h}^{-1}\right)$ and $q_{\mathrm{e}}\left(1.290 \mathrm{mmol} \mathrm{g}{ }^{-1}\right)$ were obtained by mixing the solutions in round-bottomed flasks using a laboratory shaker at $200 \mathrm{rpm}$. The adsorption of 4-CP on the activated carbon occurred fastest $\left(k_{2}=1.264 \mathrm{~g} \mathrm{mmol}^{-1} \mathrm{~h}^{-1}\right)$ and the most effective $\left(q_{\mathrm{e}}=1.520 \mathrm{mmol} \mathrm{g}^{-1}\right)$ when being mixed with a mechanical stirrer at $500 \mathrm{rpm}$. Comparable results were obtained using a magnetic stirrer- $k_{2}$ and $q_{\mathrm{e}}$ values were $1.231 \mathrm{~g} \mathrm{mmol}^{-1} \mathrm{~h}^{-1}$ and $1.510 \mathrm{mmol} \mathrm{g}^{-1}$, respectively. Therefore, considering only the adsorption rate and the adsorption efficiency, the mixing of the solutions at a high speed using the mechanical or magnetic stirrers seems to be the best. These results, however, may be adulterated (inflated) by the destruction of the structure of the adsorbent during the agitation. The problem of destruction of the adsorbent structure must be also taken into account if too high stirring speeds were used. In the selection of the method of agitation, the ease of use and the ability to study multiple samples at the same time should also be considered. In this case, the laboratory shaker seems to be best as it does not damage the adsorbent and additionally allows the simultaneous study of several or dozens of samples. Also, stirring with gas bubbles is restricted and additionally troublesome because of the potential evaporation of the adsorbate.

All things considered, the agitation is a very important factor influencing the adsorption of organic compounds on activated carbon, which should be also taken into account in adsorption studies.

Acknowledgments The authors would like to thank Katarzyna Plak for her laboratory assistance.

Open Access This article is distributed under the terms of the Creative Commons Attribution 4.0 International License (http://creativecommons.org/licenses/by/4.0/), which permits unrestricted use, distribution, and reproduction in any medium, provided you give appropriate credit to the original author(s) and the source, provide a link to the Creative Commons license, and indicate if changes were made.

\section{References}

1. Dąbrowski A, Podkościelny P, Hubicki Z, Barczak M (2005) Adsorption of phenolic compounds by activated carbon-a critical review. Chemosphere 58:1049-1070

2. Foo KY, Hameed BH (2010) Detoxification of pesticide waste via activated carbon adsorption process. J Hazard Mater 175:1-11

3. Soto ML, Moure A, Dominguez H, Parajo JC (2011) Recovery, concentration and purification of phenolic compounds by adsorption: a review. J Food Eng 105:1-27

4. Moreno-Castilla C (2004) Adsorption of organic molecules from aqueous solutions on carbon materials. Carbon 42:83-94

5. Priddy SA, Hanley TR (2003) Effect of agitation on removal of acetic acid from pretreated hydrolysate by activated carbon. Appl Biochem Biotechnol 105-108:353-364

6. Shiau CY, Pan CC (2004) Adsorption of basic dyes from aqueous solution by various adsorbents. Separ Sci Technol 39:1733-1750

7. Koumanova B, Peeva-Antova P, Yaneva Z (2005) Adsorption of 4-chlorophenol from aqueous solutions on activated carbon-kinetic study. J Univ Chem Technol Metall 40:213-218

8. Jamil N, Ahsan N, Munawar MA, Anwar J, Shafique U (2011) Removal of toxic dichlorophenol from water by sorption with chemically activated carbon of almond shells-a green approach. J Chem Soc Pak 33:640-645

9. Zahoor M (2011) Effect of agitation speed on adsorption of imidacloprid on activated carbon. J Chem Soc Pak 33:305-312 
10. Omri A, Wali A, Benzina M (2012) Adsorption of bentazon on activated carbon prepared from Lawsonia inermis wood: Equilibrium, kinetic and thermodynamic studies. Arab J Chem, in press. http://dx.doi.org/10.1016/j.arabjc.2012.04.047

11. Ihsanullah Asmaly HA, Saleh TA, Laoui T, Kumar Gupta V, Atieh MA (2015) Enhanced adsorption of phenols from liquids by aluminumoxide/carbon nanotubes: comprehensive study from synthesis to surface properties. J Mol Liq 206:176-182

12. Igbinosa EO, Odjadjare EE, Chigor VN, Igbinosa IH, Emoghene AO, Ekhaise FO, Igiehon NO, Idemudia OG (2013) Toxicological profile of chlorophenols and their derivatives in the environment: the public health perspective. Sci World J 2013:1-11 Article ID 460215

13. Michałowicz J (2005) The occurrence of chlorophenols, chlorocatechols and chlorinated methoxyphenols in drinking water of the largest cities in Poland. Pol J Environ Stud 14:327-333

14. Jung MW, Ahn KH, Lee Y, Kim KP, Rhee JS, Park JT, Paeng KJ (2001) Adsorption characteristics of phenol and chlorophenols on granular activated carbons (GAC). Microchem J 70:123-131

15. Koumanova B, Peeva P, Allen SJ (2003) Variation of intraparticle diffusion parameter during adsorption of p-chlorophenol onto activated carbon made from apricot stones. $\mathrm{J}$ Chem Technol Biotechnol 78:582-587

16. Hamdaoui O, Naffrechoux E (2007) Modeling of adsorption isotherms of phenol and chlorophenols onto granular activated carbon Part I. Two-parameter models and equations allowing determination of thermodynamic parameters. J Hazard Mater 147:381-394

17. Derylo-Marczewska A, Swiatkowski A, Biniak S, Walczyk M (2008) Effect of properties of chemically modified activated carbon and aromatic adsorbate molecule on adsorption from liquid phase. Colloids Surf A 327:1-8

18. Wu FC, Tseng RL, Huang SC, Juang RS (2009) Characteristics of pseudo-second-order kinetic model for liquid-phase adsorption: a mini-review. Chem Eng J 151:1-9

19. Lorenc-Grabowska E, Gryglewicz G, Machnikowski J (2010) p-Chlorophenol adsorption on activated carbons with basic surface properties. Appl Surf Sci 256:4480-4487

20. Tseng RL, Wu KT, Wu FC, Juang RS (2010) Kinetic studies on the adsorption of phenol, 4-chlorophenol, and 2,4-dichlorophenol from water using activated carbons. J Environ Manage 91:2208-2214

21. Kuśmierek K, Sankowska M, Świątkowski A (2014) Kinetic and equilibrium studies of simultaneous adsorption of monochlorophenols and chlorophenoxy herbicides on activated carbon. Desalin Water Treat 52:178-183

22. Kuśmierek K, Świątkowski A, Syga P, Dąbek L (2014) Influence of chlorine atom number in chlorophenols molecules on their adsorption on activated carbon. Fresenius Environ Bull 23:947-951

23. Strachowski P, Bystrzejewski M (2015) Comparative studies of sorption of phenolic compounds onto carbon-encapsulated iron nanoparticles, carbon nanotubesand activated carbon. Colloids Surf A 467:113-123

24. Kuśmierek K, Świątkowski A (2015) The influence of an electrolyte on the adsorption of 4-chlorophenol onto activated carbon and multi-walled carbon nanotubes. Desalin Water Treat, in press. doi: 10.1080/19443994.2014.965221

25. Hameed BH, Chin LH, Rengaraj S (2008) Adsorption of 4-chlorophenol onto activated carbon prepared from rattan sawdust. Desalination 225:185-198

26. Korver JA (1950) Production of ash-free active carbon. Chem Weekbl 46:301-302

27. Lagergren S (1898) Theorie der sogenannten adsorption geloester stoffe. Vetensk Handl 24:1-39

28. Ho YS, McKay G (1999) Pseudo-second-order model for sorption processes. Process Biochem $34: 451-465$ 